\title{
INFLUENCE OF GEOMETRICAL MAGNIFICATION ON COMPUTED TOMOGRAPHY DIMENSIONAL MEASUREMENTS
}

\author{
Amalija Horvatić Novak, Biserka Runje, Danijel Butković
}
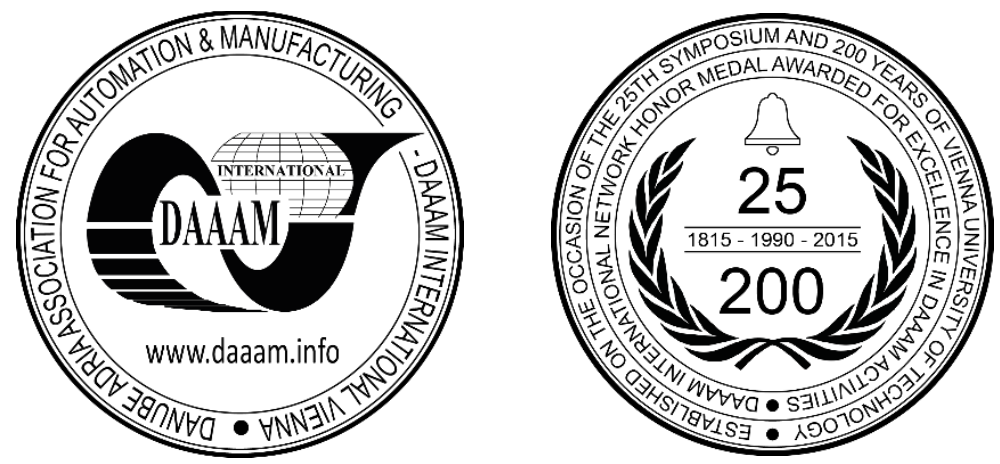

This Publication has to be referred as: Horvatic, A[malija]; Runje, B[iserka] \& Butkovic, D[anijel] (2016). Influence of Geometrical Magnification on Computed Tomography Dimensional Measurements, Proceedings of the 27th DAAAM International Symposium, pp.0615-0622, B. Katalinic (Ed.), Published by DAAAM International, ISBN 978-3-90273408-2, ISSN 1726-9679, Vienna, Austria

DOI: $10.2507 / 27$ th.daaam.proceedings.090

\begin{abstract}
Computed tomography is a widely used method in the field of dimensional measurements. It is a non-contact, non-destructive measurement method that enables insight into both external and internal geometry of measured part which allows measurement of characteristics otherwise unreachable with tactile measurement methods. The biggest problem with computed tomography measurements is lack of metrological traceability. Because of the fact that a lot of parameters influence the whole measurement system, measurement uncertainty is still not evaluated. In this paper, influence of one of the influencing parameters, geometrical magnification, on results of dimensional and geometrical measurement characteristics was observed. Besides experimental research, simulations of computed tomography scanning were done. Measurement results obtained from both scanned and simulated models were compared and observed with regard to reference values. Results obtained from scanned model showed predictable behaviour compared to results obtained from simulated model.
\end{abstract}

Keywords: Computed tomography; dimensional measurements; influence parameters; geometrical magnification.

\section{Introduction}

Computed tomography - CT is a new method used in the field of dimensional measurements. It is a non-contact, non-destructive measurement method that enables insight into both external and internal geometry of measured part which allows measurement of characteristics otherwise unreachable with tactile measurement methods. Computed tomography uses X-ray for obtaining large number of 2D scans that arise during rotation of part for 360 degrees, which are later used for rendering real 3D model of measured part. Concerning the fact that this is a new dimensional measurement method with a large number of influencing parameters, measurement uncertainty is still unknown and metrological traceability is still not achieved [1-5]. With aim to assure metrological traceability, identification of all influencing parameters and their contribution to measurement uncertainty is necessary. In this paper influence of geometrical magnification on measurement results has been analyzed. Also, comparison of measured results obtained from real scanned model and simulated model was done. Experimental scanning was performed on CT device for dimensional measurements produced by Nikon, model XT H 225, while simulation of X-ray scanning were performed in software package 'aRTist - trial 
version' (analytical Radiographic Testing inspection simulation tool) by BAM (Federal Institute for Materials Research and Testing) [6-8].

Selected object for this analysis was cylinder made from aluminium, and the following dimensional characteristics were observed: inner and outer diameter and cylinder length, and geometrical characteristics: coaxiality and parallelism.

\section{Usage of computed tomography in dimensional measurements}

Computed tomography method is known for over 40 years when it was first implemented in field of medicine, and later from 1980s in field of material analysis [9]. Idea for applying computed tomography for dimensional measurements emerged at the beginning of 1990s when first dimensional measurement was done. Accuracy of obtained results was about $0.1 \mathrm{~mm}$ [10]. After that event, significant development of CT devices suitable for dimensional measurements has begun. First CT device for dimensional measurement was presented in 2005 on Control Fair in Sinsheim, Germany by producer Werth Messtechnik GmbH [11]. Today, computed tomography method is widely used in field of dimensional measurement, but a problem with lack of measurement uncertainty and connected to that, lack of metrological traceability is still present [12-14]. In order to achieve metrological traceability, it is necessary to assess measurement uncertainty of measured results. Parameters influencing the whole CT measurement process contribute to measurement uncertainty, so the first step in addressing measurement uncertainty is identification of all influencing parameters. Considering the fact that process of dimensional measurement with computed tomography consists from three separate sub-processes, influencing parameters can be divided into three sub-classes: parameters influencing scanning process, parameters influencing modelling process and parameters influencing measurement process. On the other hand, some authors [1517] classified influencing parameters as: environmental parameters, hardware parameters, software parameters, object related parameters and influence of operator. Here, classification of parameters considers hardware parameters, software parameters and other parameters and it is given in Table 1.

\begin{tabular}{|c|c|c|}
\hline $\begin{array}{l}\text { Hardware } \\
\text { influencing } \\
\text { parameters }\end{array}$ & $\begin{array}{c}\text { Software } \\
\text { influencing } \\
\text { parameters } \\
\end{array}$ & $\begin{array}{c}\text { Other } \\
\text { influencing } \\
\text { parameters }\end{array}$ \\
\hline $\begin{array}{ll}- & \text { X-ray source } \\
- & \text { Rotational } \\
\text { table } \\
\text { - } \quad \text { X-ray sensor } \\
\text { (detector) }\end{array}$ & $\begin{array}{ll}- & \text { 3D reconstruction } \\
- & \text { Surface determination } \\
- & \text { Software correction of } \\
& \text { beam hardening, noise } \\
& \text { reduction and scattering }\end{array}$ & $\begin{array}{ll}\text { - } & \text { Influence of measured part (dimensions, } \\
\text { geometry, surface characteristics - } \\
\text { roughness) }\end{array}$ \\
\hline
\end{tabular}

Table 1. Classification of CT system influencing parameters

One of the parameters related to operator is position of the measured part, and connected with that the parameter of geometrical magnification. Geometrical magnification (1) is defined as ratio between source-to-detector distance $(S D)$ and source-to-object $(\mathrm{SO})$ distance.

$$
\text { Geometrical magnification }=\frac{S D}{S O}
$$

By positioning the object closer to X-ray source, larger resolution can be achieved, but at the same time, picture of the scanned object results in less sharp edge projection with appearance of so called penumbra effect [15]. In standard CT systems, source-to-detector distance is constant, so geometrical magnification depends only on source-to-object distance. With increase of source-to-object distance, geometrical magnification decreases. Lower geometrical magnification means lower resolution, but enables scanning of the whole part, especially when large size objects are investigated. Influence of geometrical magnification on CT measurement results is significant, where deviations in results increase with increase of geometrical magnification [18-20]. In this paper object with simple geometry, aluminium cylinder has been investigated in order to obtain behaviour of results depending on geometrical magnification and define deviations in results obtained by scanning and simulations. Observed were three dimensional characteristics: outer diameter $D$, inner diameter $d$ and length $l$ and two geometrical characteristics: parallelism of top and bottom cylinder planes and coaxiality between outer and inner cylinders. 


\section{Experimental research}

Experimental researches consist of:

- $\quad$ performance of CT scanning real part, data processing and measurement of reconstructed 3D model,

- performance of CT simulation, where the same scanning settings as in real scanning process were chosen.

\subsection{CT measurements}

CT scanning was performed on industrial CT device by Nikon, model XT H 225. Chosen scanning parameters are given in Table 2 and Table 3. With the fact that in this research influence of one parameter, geometrical magnification was investigated, other scanning parameters were kept constant. Table 2 presents scanning parameters set for all five cases while in Table 3 are given source-to-object distances and amounts of geometrical magnification according to (1).

\begin{tabular}{|l|c|}
\hline \multicolumn{1}{|c|}{ Parameter } & Amount \\
\hline Voltage, $\mathrm{kV}$ & 130 \\
\hline Current, $\mu \mathrm{A}$ & 30 \\
\hline No.of projections & 1000 \\
\hline Detector size, pixels & $3192 \times 2296$ \\
\hline Pixel size, $\mu \mathrm{m}$ & $127 \times 127$ \\
\hline X-ray spot size, $\mu \mathrm{m}$ & 3.9 \\
\hline
\end{tabular}

Table 2. Scanning parameters

\begin{tabular}{|c|c|c|c|c|c|}
\hline \multirow{2}{*}{ Parameter } & \multicolumn{5}{|c|}{ Experiment No. } \\
\cline { 2 - 6 } & $\mathbf{1}$ & $\mathbf{2}$ & $\mathbf{3}$ & $\mathbf{4}$ & $\mathbf{5}$ \\
\hline $\begin{array}{c}\text { Source-to-object } \\
\text { distance, mm }\end{array}$ & 200 & 300 & 400 & 500 & 600 \\
\hline $\begin{array}{c}\text { Geometrical } \\
\text { magnification }\end{array}$ & 4.921 & 3.281 & 2.461 & 1.968 & 1.640 \\
\hline
\end{tabular}

Table 3. Source-to-object distances

CT models of scanned parts were generated with usage of software package CT-Pro, and measurements were performed in software VGStudio Max 2.2. Chosen measurement strategy involved fitting simple geometry objects where both outer and inner diameters were fitted with cylinders, using Gaussian approach; length was measured as a distance between two planes; parallelism was observed as a geometrical measurand of two planes, and coaxiality was observed between outer and inner cylinders (Table 4).

\begin{tabular}{|c|c|}
\hline Measurand & Strategy \\
\hline Outer diameter, $D, \mathrm{~mm}$ & Cylinder \\
\hline Inner diameter, $d, \mathrm{~mm}$ & Cylinder \\
\hline Lenght, $l, \mathrm{~mm}$ & Plane - Plane \\
\hline Parallelism & Plane - Plane \\
\hline Coaxiality & Cylinder - Cylinder \\
\hline
\end{tabular}

Table 4. Measuring strategy for CT measurements

\subsection{CT simulations}

CT simulations were conducted in software for radiographic testing named 'aRTist' (analytical Radiographic Testing inspection simulation tool), developed by Bundesanstalt für Materialforschung und-prüfung, BAM, Germany. For simulation of the CT process, modules aRTist image view and Ct scan were used. Program setups were the same as real setups and limitations of Nikon XT H 225 device. The same input scanning parameters as the one used for CT scanning of the real part, stated in Tables 2 and 3 were chosen. CAD model of cylinder made according to the actual reference values was simulated. Figure 1 presents drawing of simulated cylinder. 

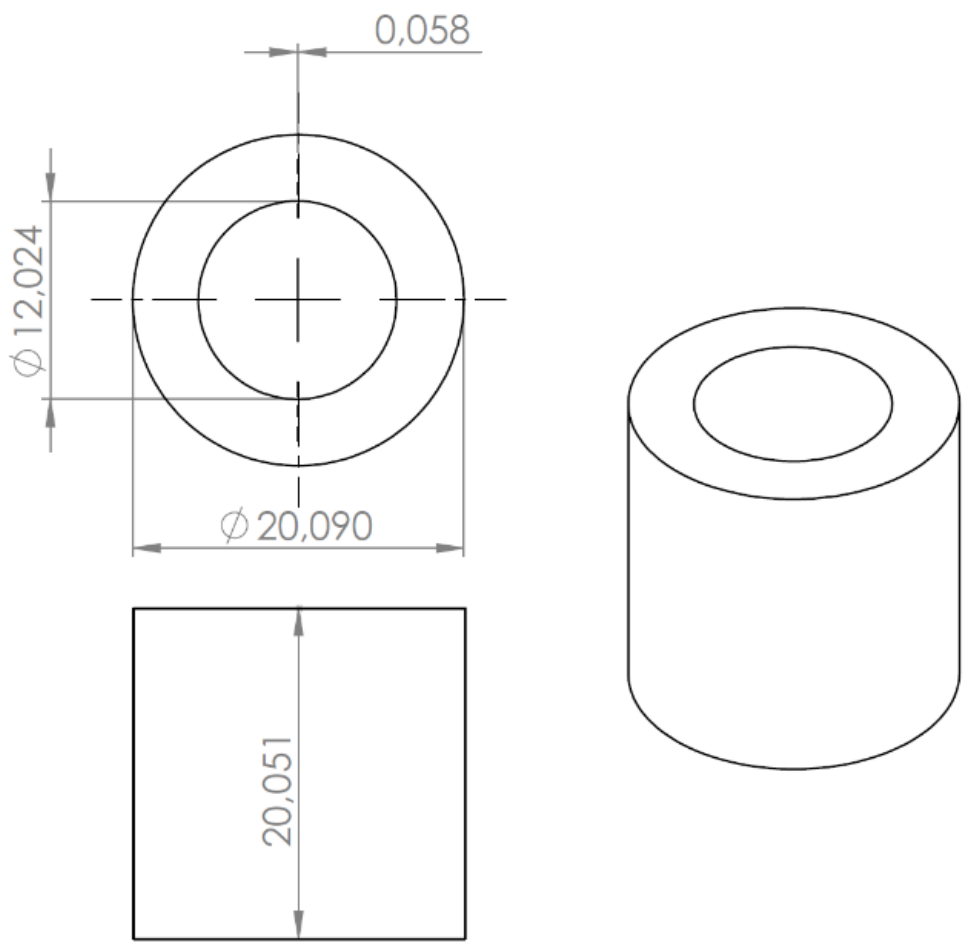

Figure 1. Drawing of cylinder with dimensions and model of cylinder

Models generated with usage of aRTist were also analyzed with software packages for measurements and data analysis VGStudio Max 2.2. The same measurement method was used for measurement performance on simulated models (Table 4.).

\section{Results}

Results are given graphically as deviations of experimentally obtained results of CT scanning from reference values and as deviations of results from simulation obtained scanned model and measured results from reference values. Deviations are given on the same graph.

Reference measurements were performed on coordinate machine Ferranti Merlin and measurements were done in software MODUS. The reproducibility was obtained by measuring the cylinder three times in different days during the period of two weeks. Table 5 presents measured results and related measurement uncertainties of dimensional and geometrical characteristics.

\begin{tabular}{|c|c|c|}
\hline Measurand & Measured results & $\begin{array}{c}\text { Expanded } \\
\text { measurement uncertainty } U, \\
k=2, P=95 \%, \mu \mathrm{m}\end{array}$ \\
\hline Outer diameter, $D, \mathrm{~mm}$ & 20.098 & 4 \\
\hline Inner diameter, $\mathrm{d}, \mathrm{mm}$ & 12.017 & 4 \\
\hline Length, $l, \mathrm{~mm}$ & 20.063 & 4 \\
\hline Parallelism, mm & 0.055 & 1 \\
\hline Coaxiality, mm & 0.019 & 1 \\
\hline
\end{tabular}

Table 5. Reference values

Results obtained from CT measurements for outer diameter presented in Figure 1 show almost linear fall in amount with increase of source-to-object distance. Deviations of measured results obtained in CT simulations show decline in value of cylinder outer diameter with increase of source-to-object distance until the amount of source-to-object distance reaches $400 \mathrm{~mm}$. After that, the value of outer diameter starts to grow significantly. The best agreement between results obtained from CT measurements and CT simulations are in the source-to-object distance range 300-400 mm, which equals geometrical magnification range between 3.281 and 2.461 . 


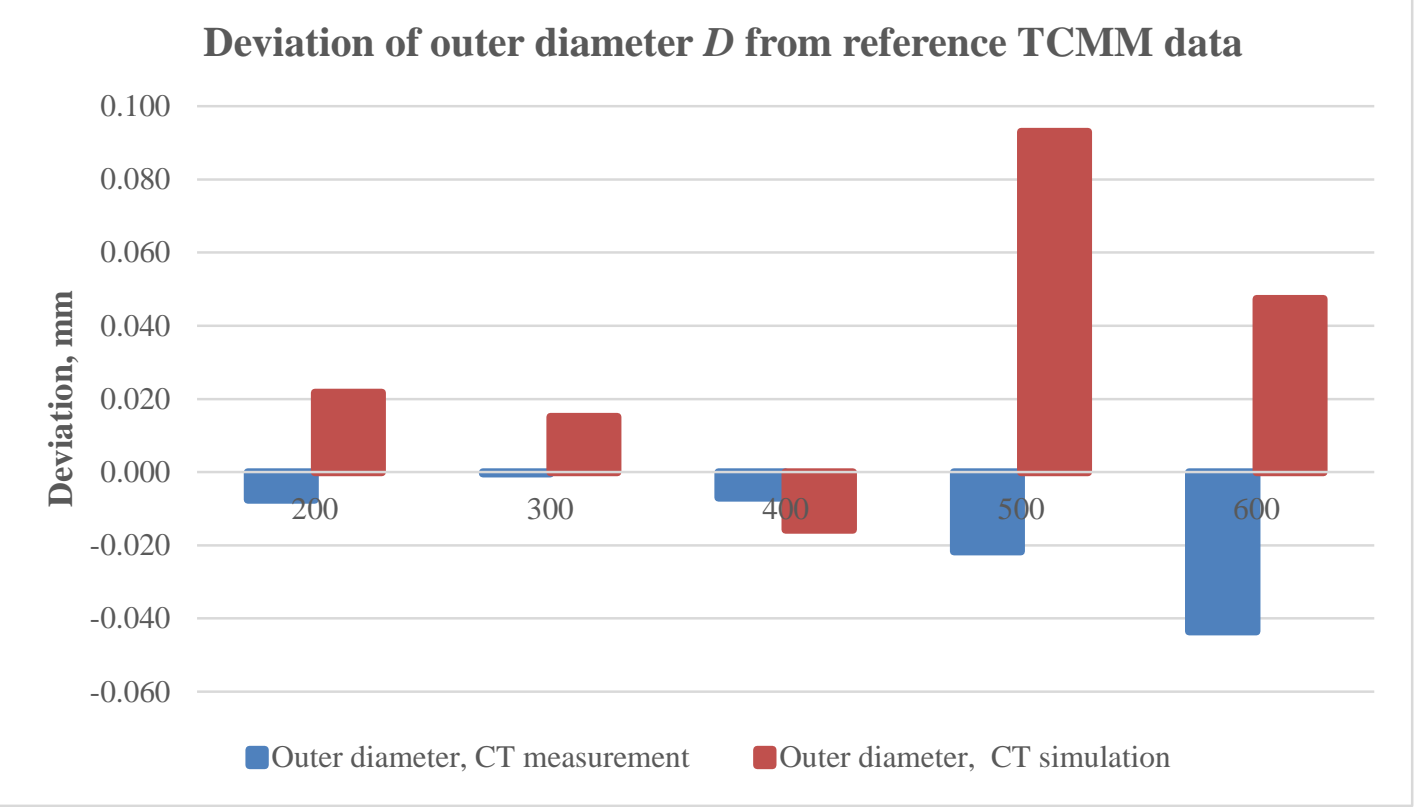

Figure 2. Deviation of outer diameter from reference values

Figure 3 shows deviations of cylinders inner diameter from reference values in dependence of source-to-object distance. Results obtained in CT measurements show increase of deviation in inner diameter with increasing source-toobject distance. Behaviour of simulated results shows significant decrease of deviation in inner diameter until the amount of source-to-object distance equals $400 \mathrm{~mm}$ and from $400 \mathrm{~mm}$ to $600 \mathrm{~mm}$ slight decline in results is observed.

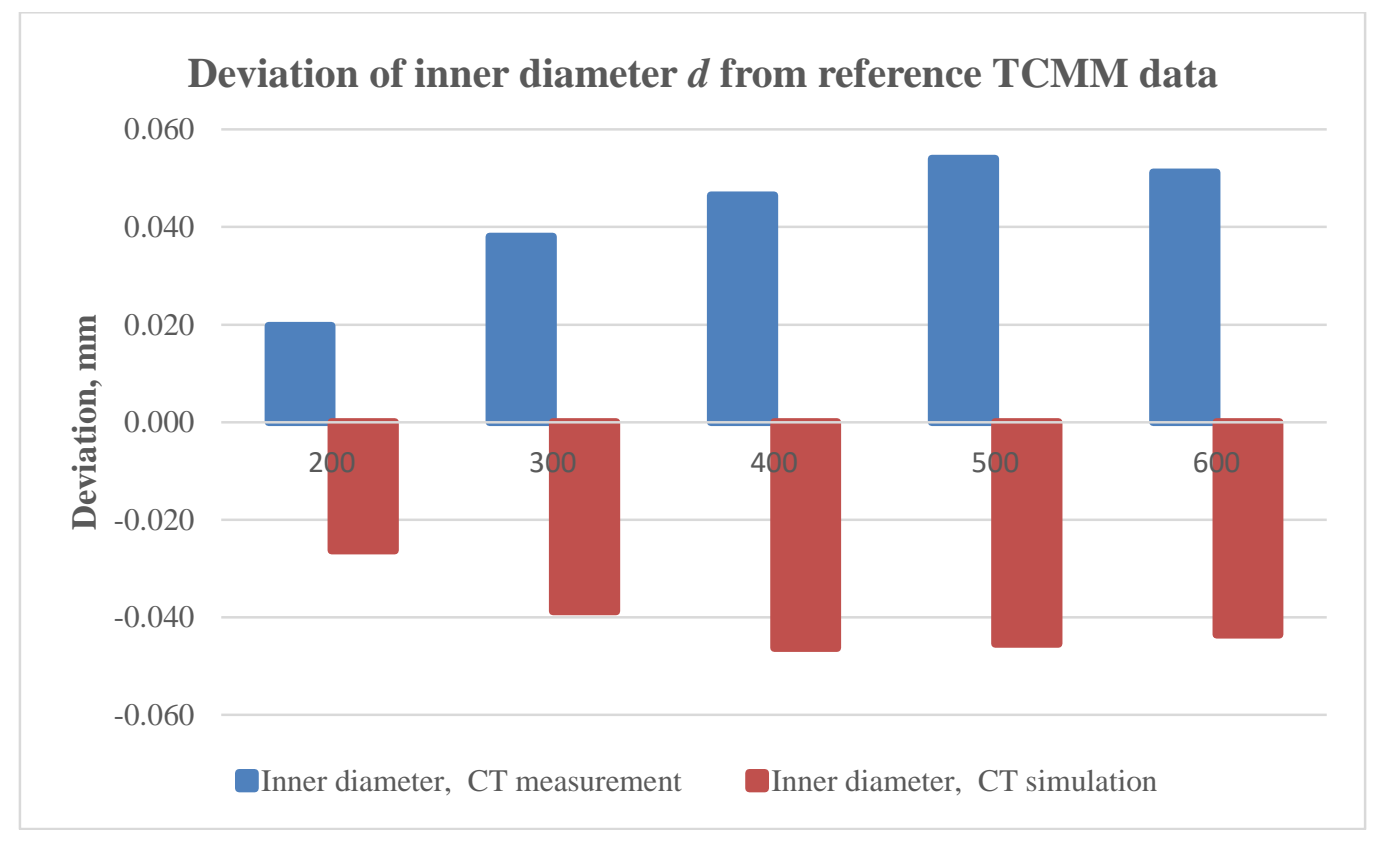

Figure 3. Deviation of inner diameter from reference values

In the Figure 4 an increase in deviation of cylinder length with increase of source-to-object distance from $200 \mathrm{~mm}$ to $400 \mathrm{~mm}$ distances, for results obtained by CT measurements, is visible. Maximal deviation between cylinder length and reference value is noted for distances from X-ray source in the range of $300 \mathrm{~mm}$ to $400 \mathrm{~mm}$, while the best results are obtained when the object is as close as possible to X-ray source, but also in the case when object is the nearest to the detector. Simulated results on the other hand show the biggest deviation from reference value in case where the object is near the X-ray source. Measured and simulated results in dependence of geometrical magnification showed the biggest discrepancy in case of length measurements. 


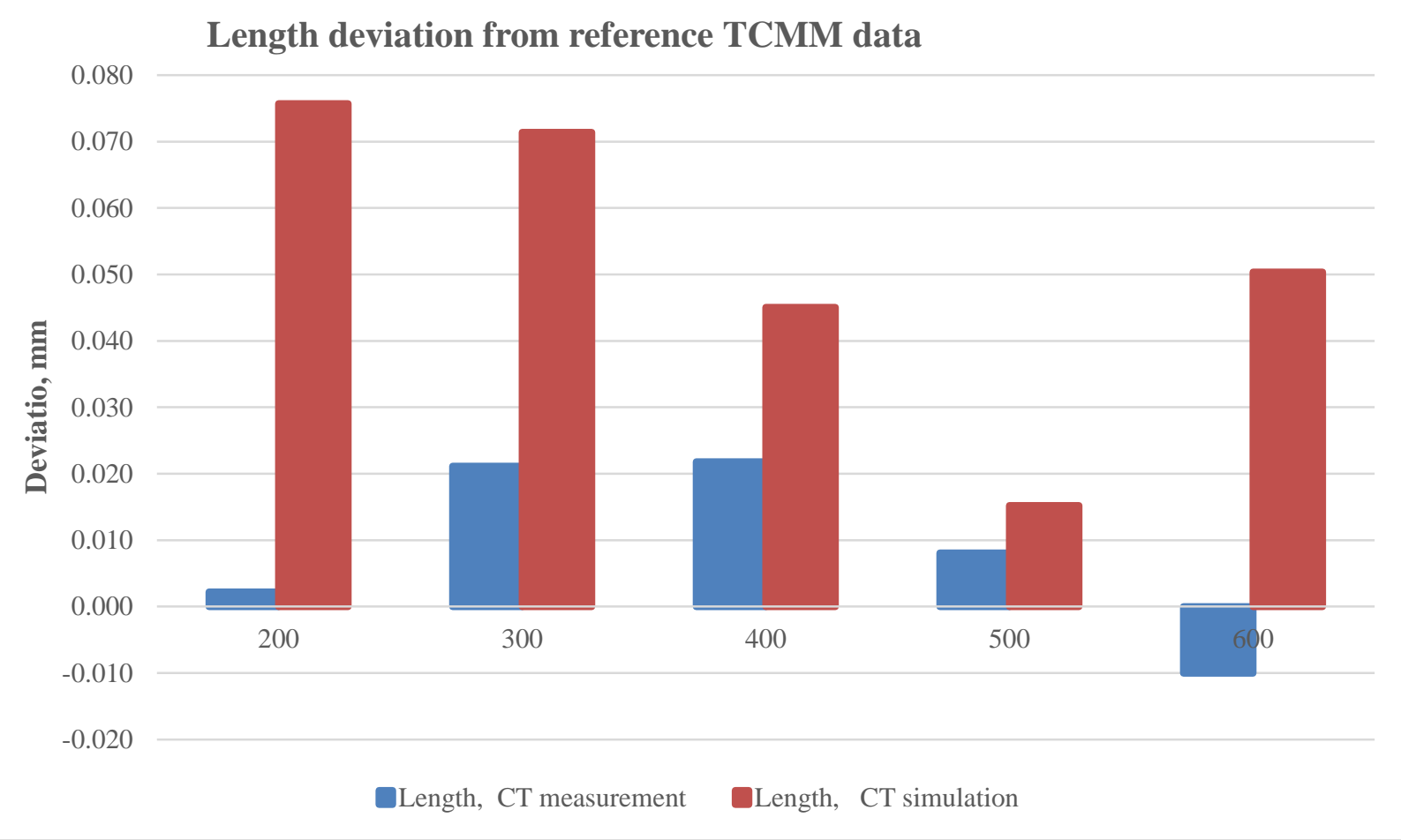

Figure 4. Length deviation from reference values

From geometrical characteristics, parallelism and coaxiality were observed. Results of parallelism obtained from CT measurements and the one obtained from CT simulations show equal behaviour with increase of source-to-object distance (Figure 5).

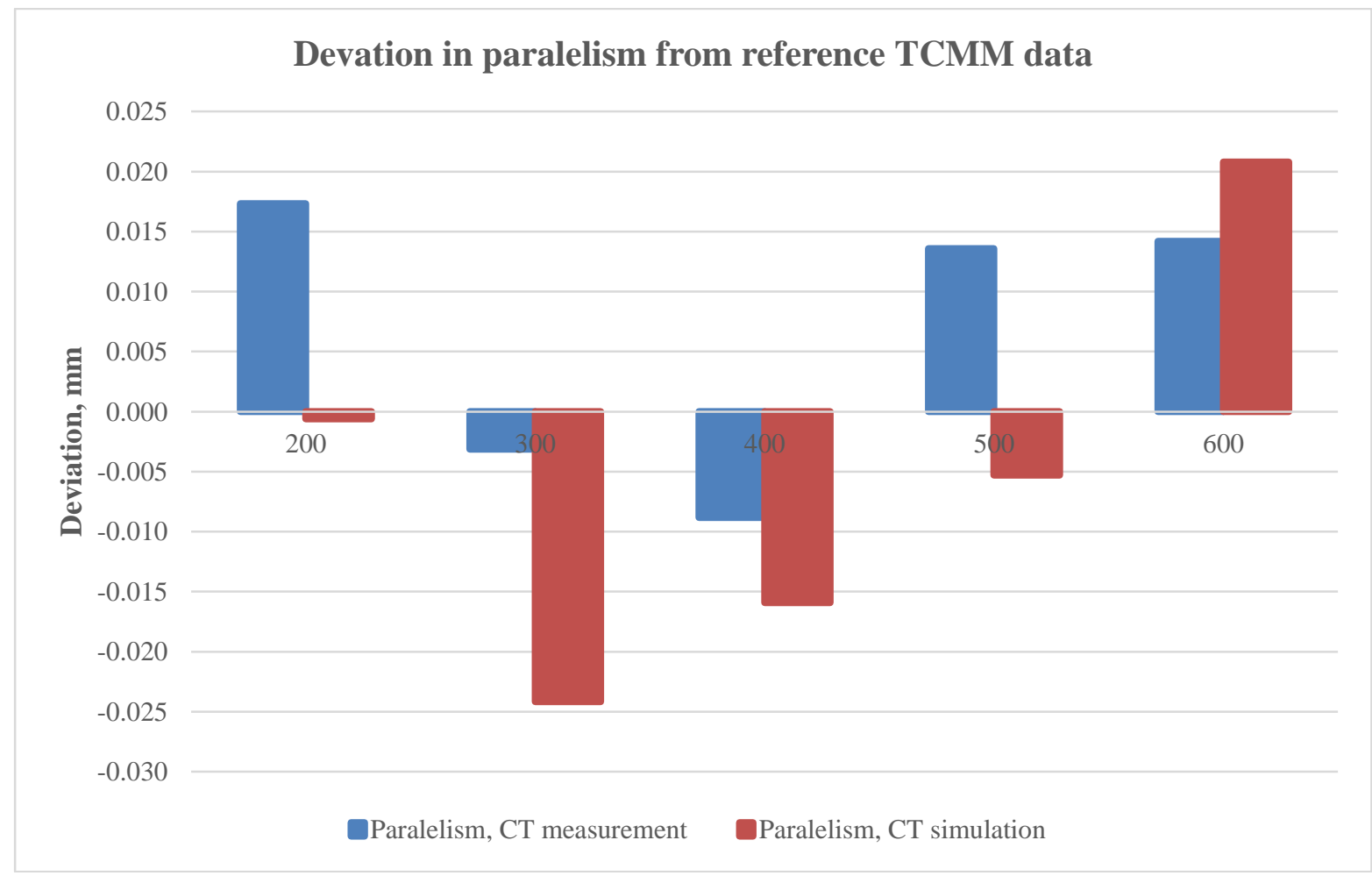

Figure 5. Deviation in parallelism from reference values 


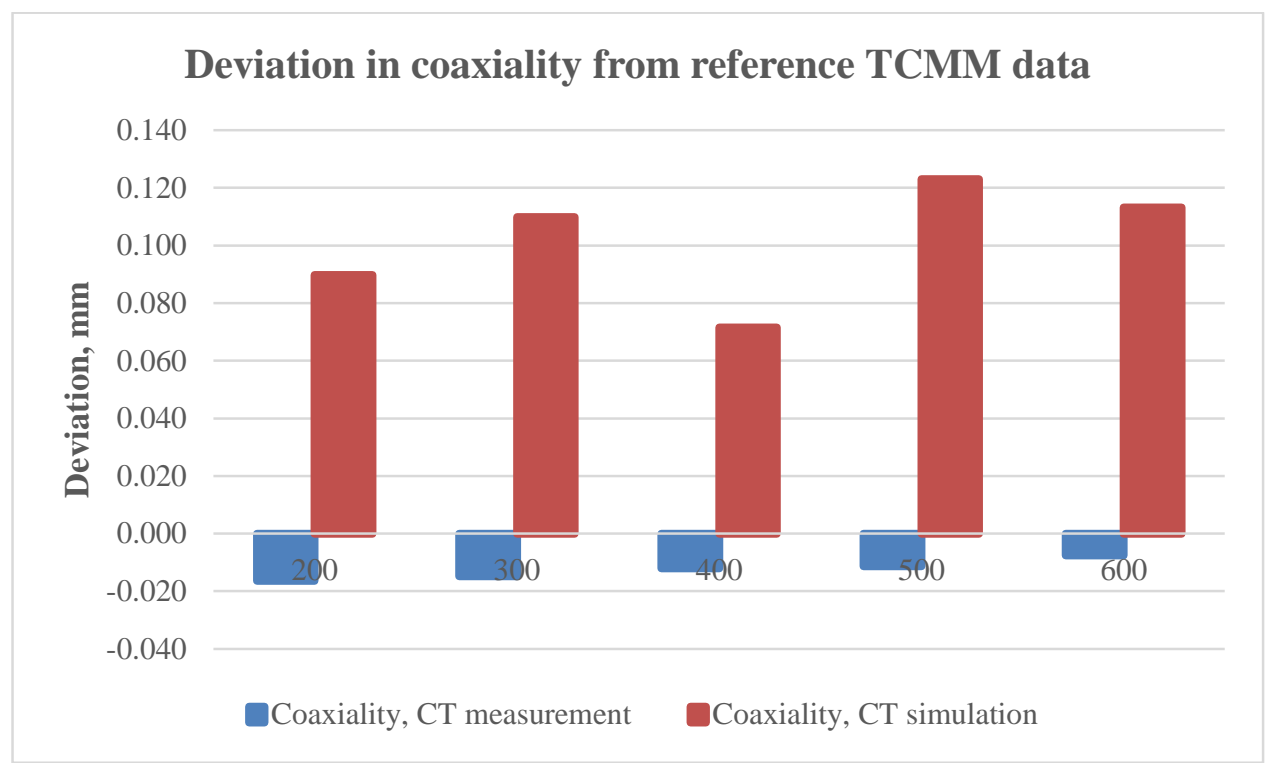

Figure 6. Deviation in coaxiality from reference values

Results of coaxiality (Figure 6.) obtained from CT measurement show invariance with increase of source-to-object distance. On the other hand, results obtained from CT simulations behave totally unpredictable.

\section{Conclusion}

In this research measurements of dimensional and geometrical characteristics were monitored. Dimensional characteristic of outer and inner diameter, as well as length of the aluminium cylinder were observed. Research included observation of influence parameter geometrical magnification on measurement results obtained with usage of computed tomography. Two approaches were conducted, first one included performance of experiment on CT device Nikon X TH 225 while second approach was simulation of CT scanning process by using simulation software for radiographic testing 'aRTist' (analytical Radiographic Testing inspection simulation tool), developed by Bundesanstalt für Materialforschung und-prüfung, BAM, Germany. Observed were deviations of measured characteristics from reference values obtained on coordinate tactile measurement machine. Obtained results showed significant deviations from reference values. General conclusion is that results obtained by CT scanning behave in predictable way, where results of outer diameter fall with decrease of geometrical magnification, while results of inner diameter rise with decrease of geometrical magnification parameter. Results obtained by CT simulation in case of outer diameter showed good agreement with reference values for source-to-object distance from $200 \mathrm{~mm}$ to $400 \mathrm{~mm}$, while results in case of higher source-to-object distance showed unpredictable leap. The same unpredictable leap in results obtained by CT scanning occurs in length measurement for source-to-object distance from $500 \mathrm{~mm}$ and over. Observation of geometrical characteristics results depending on geometrical magnification showed, in case of parallelism similarities within results obtained by scanning and simulations. Obtained results deviate from reference values approximately $0.020 \mathrm{~mm}$ in absolute amount. On the other hand results of coaxiality obtained by CT scanning showed invariance on geometrical magnification change, while results obtained by CT simulation behave totally unpredictable and deviate from reference values for about $0.100 \mathrm{~mm}$.

Further step in research in a field of computed tomography dimensional measurement and achievement of metrological traceability should include evaluation of components of measurement uncertainty with further aim to asses measurement uncertainty of results obtained with CT measurement method which is basis for achievement of metrological traceability.

\section{Acknowledgments}

The authors would like to thank BAM (Federal Institute for Materials Research and Testing) for providing the simulation tool 'aRTist' - trial version in duration of one month.

\section{References}

[1] Carmignato, S.; Pierobon, A.; Rampazzo, P.; Parisatto, M. \& Savio, E. (2012). CT for Industrial Metrology Accuracy and Structural Resolution of CT Dimensional Measurements, Proceedings of ICT, Conference on Industrial Computed Tomography, Wels, Austria

[2] Müller, P.; Hiller, J.; Cantatore, A. \& De Chiffre, L. (2011). Investigation of measuring strategies in computed tomography, Proceedings of the International conference on Advanced Manufacturing Engineering, Brno, Czech Republic 2011, pp. 31-42 
[3] Müller, P.; Hiller; J., Dai; Y., Andreasen; J.L., Hansen H.N. \& De Chiffre, L. (2014). Estimation of measurement uncertainties in X-ray computed tomography metrology using substitution method, CIRP Journal of Manufacturing Science and Technology Vol. 7, No. 3, 2014, pp. 222-232, doi:10.1016/j.cirpj.2014.04.002

[4] Müller, P; Cantatore, A; Andreasen, J.L.; Hiller, J. \& De Chiffre, L. (2013). Computed tomography as a tool for tolerance verification of industrial parts. Proceedings of 12th CIRP Conference on Computer Aided Tolerancing. Doi: 10.1016/j.procir.2013.08.022

[5] Carmignato, S. (2012). Computed tomography as a promising solution for industrial quality control and inspection of castings. Metallurgical Science and Technology Vol. 30-1, 2012, pp.5-14

[6] Bellon, C \& Jaenisch, G.-R. (2007). aRTist - Analytical RT Inspection Simulation Tool. Proceedings of DIR 2007 International Symposium on Digital industrial Radiology and Computed Tomography, June 25-27, Lyon, France.

[7] Jaenisch, G.-R.; Bellon, C \& Ewert, U. (2008). aRTist-Analytical RT Inspection Simulation Tool for Industrial Application. Proceedings of 17th World Conference on Nondestructive Testing, October 25-28, Shanghai, China.

[8] Bellon, C; Deresch, A; Gollwitzer, C \& Jaenisch, G.-R. (2012). Radiographic Simulator aRTist: Version 2. Proceedings of 18th World Conference on Nondestructive Testing, April 16-20, Durban, South Africa.

[9] Gapinski, B.; Wieczorowski, M.; Marciniak-Podsadna, L.; Dybala, B. \& Ziolkowski, G. (2013). Comparison of Different Method of Measurement Geometry using CMM, Optical Scanner and Computed Tomography 3D, Procedia Engineering 69, 24th DAAAM International Symposium on Intelligent Manufacturing and Automation, Zadar, Katalinic, B. (Ed.), pp.255-262, Elsevier, DOI:10.1016/j.proeng.2014.02.230

[10] Kruth, J.P.; Bartscher, M.; Carmignato, S.; Schmidt, R.; De Chiffre, L. \& Weckenmann A. (2011). Computed tomography for dimensional metrology, CIRP Annals - Manufacturing Technology Vol. 60, No. 2, 2011, pp.821842, ISSN 0007-8506; DOI 10.1016/j.cirp.2011.05.006

[11] http://www.control-messe.de/en/nc/exhibitors/exhibitors-information/trade-fairprofile/?cHash=0844b798ad4d75440af67c0013350c7e\&sword_list\%5B0\%5D=2005, Accessed on: 2016-03-04

[12] Carmignato, S. Accuracy of industrial computed tomography measurements:Experimental results from an international comparison. CIRP Annals - Manufacturing Technology Vol. 61, 2012, pp.491-494, ISSN 0007-8506; DOI: /10.1016/j.cirp.2012.03.021

[13] Hiller, J. \& Reindl, L.M. (2012). A computer simulation platform for the estimation of measurement uncertainties in dimensional X-ray computed tomography. Measurement Vol. 45, 2012, pp.2166-2182. DOI: 10.1016/j.measurement.2012.05.030

[14] Affenzeller, C; Gusenbauer, C; Reiter, M \& Kastner, J. (2015). Measurement uncertainty evaluation of an X-ray computed tomography system. Proceedings of Digital Industrial Radiology and Computed Tomography (DIR 2015), June 22-25, Ghent, Belgium.

[15] Welkenhuyzen, F.; Kiekens, K.; Pierlet, M.; Dewulf, W.; Bleys, P.; Kruth, J.-P. \& Voet A. (2009). Industrial Computer Tomography for Dimensional Metrology: Overview of Influence Factors and Improvement Strategies, OPTIMESS2009 proceedigsbook, $4^{\text {th }}$ International Conference on Optical Measurement Techniques for Structures and Systems, Antwerp, Buytaert, J \& Dirck J.J. (Eds.), ISBN 978-90-423-0366-9

[16] Cantatore, A. \& Müller, P. (2011). Introduction to computed tomography, Kgs.Lyngby: DTU Mechanical Engineering

[17] Sun, W.; Brown, S.B. \& Leach, R.K. (2012) An overview of industrial X-ray computed tomography, NPL Report, Teddington

[18] Müller, P.; Hiller, J.; Cantatore, A.; Bartscher, M. \& De Chiffre L. (2012). Investigation on the influence of image quality in X-ray CT metrology, Paper presented at 4th Conference on Industrial Computed Tomography (iCT), Wels, Austria

[19] Weckenmann, A \& Krämer, P. (2009). Assesment of measurement uncertainty caused in the preparation of measurements using computed tomography. Proceedings of XIX IMEKO World Congress Fundamental and Applied Metrology, September 6-11, 2009, Lisbon, Portugal.

[20] Weckenmann, A \& Krämer. (2010). Chapter 17 in Product Lifecycle Management: Geometric Variations. Eds. Max Giordano, Luc Mathieu and François Villeneuve, ISTE Ltd. Published 2010 by ISTE Ltd. 